\title{
W comme WINSTUBS
}

Bilder aus vergangener Zeit de Léo Schnug (1909)

\section{Cédric Oberlé}

\section{OpenEdition}

\section{Journals}

Édition électronique

URL : https://journals.openedition.org/rbnu/1852

DOI : $10.4000 /$ rbnu. 1852

ISSN : 2679-6104

Éditeur

Bibliothèque nationale et universitaire de Strasbourg

\section{Édition imprimée}

Date de publication : 1 mai 2014

Pagination : 76-79

ISBN : 9782859230524

ISSN : 2109-2761

Référence électronique

Cédric Oberlé, "W comme WINSTUBS », La Revue de la BNU [En ligne], 9 | 2014, mis en ligne le 01 mai 2014, consulté le 23 mai 2021. URL : http://journals.openedition.org/rbnu/1852 ; DOI : https://doi.org/ 10.4000/rbnu. 1852

\section{(c) (i) (2)(2)}

La Revue de la BNU est mise à disposition selon les termes de la Licence Creative Commons Attribution - Pas d'Utilisation Commerciale - Partage dans les Mêmes Conditions 4.0 International. 


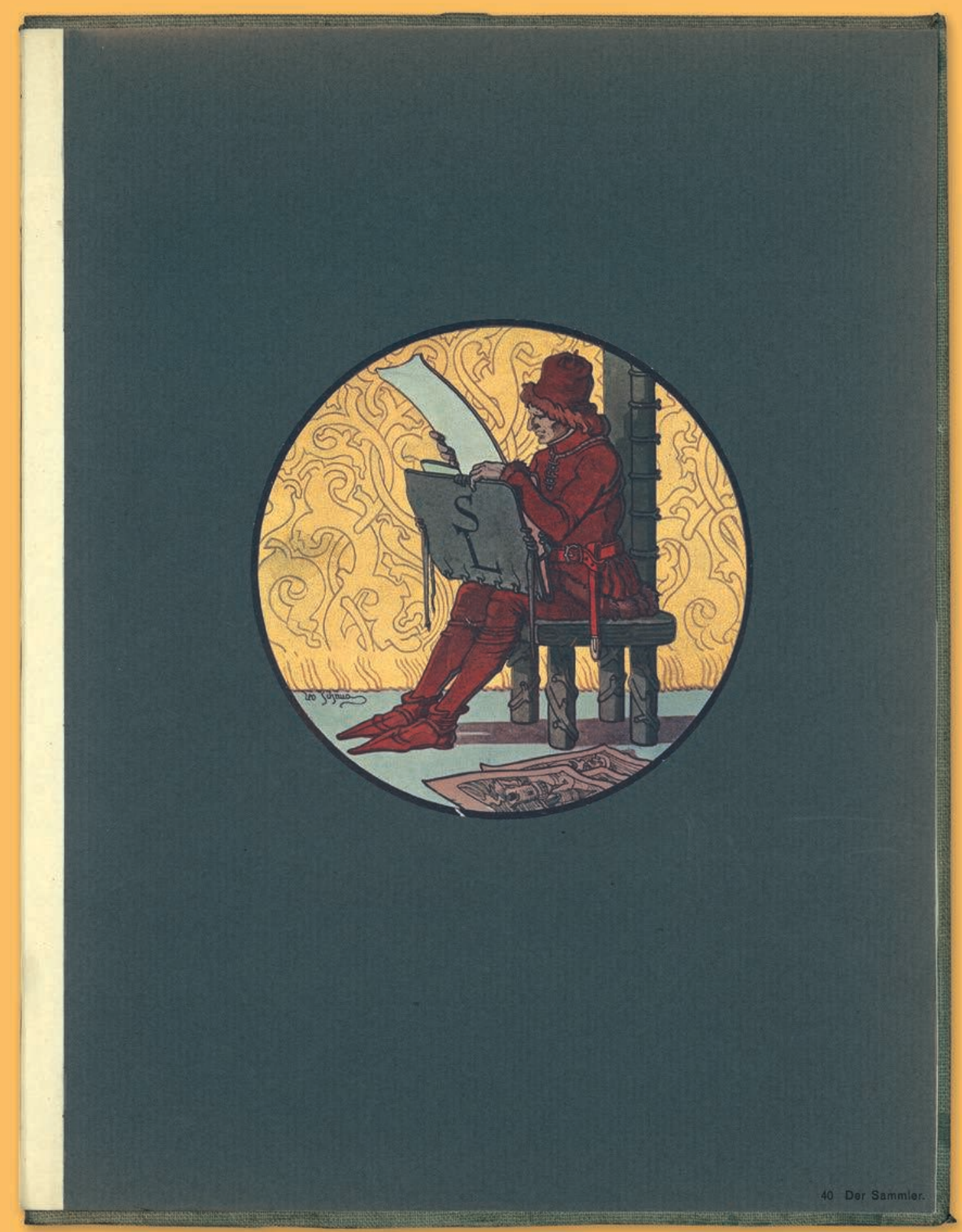


Trésors de l'écrit : un abécédaire

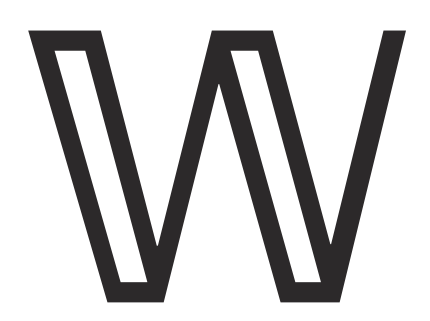

\section{WINSTUBS \\ Bilder aus vergangener Zeit \\ de Léo Schnug (Igog)}

Bilder aus vergangener Zeit se compose de quarante lithographies, réalisées par Léo Schnug (1878-1933) entre 1900 et 1909 . La BNU possède deux exemplaires de l'ouvrage. Préfacé par le peintre et critique d'art Theodor Knorr, il paraît en 1909 chez Julius Manias (1866-1944). Ce n'est pas la première collaboration entre les deux hommes. Dès 1904, Schnug dessine une série de cartes postales éditées par Manias. Ce dernier, imprimeur et éditeur originaire de Kehl, fonde en 1891 à Strasbourg la Graphische Kunstdruckerei, entreprise qui connaît un véritable essor au tournant du $20^{\mathrm{e}}$ siècle.

Enfant turbulent et indiscipliné, Léo Schnug montre très tôt des aptitudes pour le dessin. Son père, Heinrich Schnug, est greffier et fait partie des fonctionnaires d'origine allemande nouvellement installés dans la région suite à l'annexion. Souffrant de troubles mentaux, il est interné dès 1880 . Sa mère subvient aux besoins du foyer en louant des chambres à des comédiens de l'opéra et à des militaires. Cela exerça une influence déterminante sur le jeune Schnug dans son attrait pour les costumes. Il est d'abord étudiant aux Arts décoratifs de Strasbourg, puis à l'Académie des beaux-arts de Munich, où il se lie avec un autre Alsacien, Henri Loux. Dès 17 ans, Schnug illustre des livres pour les éditeurs viennois Gerlach et Schenk, grâce à l'entremise de son professeur strasbourgeois, le peintre Anton Seder. Par la suite, il participe à l'illustration de divers ouvrages. Notons en 1905 sa collaboration à la première édition du recueil de poèmes de Georges Spetz, Les Légendes d'Alsace, avec ses amis Charles Spindler et surtout Joseph Sattler dont il est proche stylistiquement. Artiste fécond, Schnug réalise de nombreux ex-libris, menus ou affiches. S'il appartient au groupe d'artistes du "Kunschthafe " et a des affinités avec ceux du Cercle de Saint-Léonard, il fréquente plus assidûment les winstubs strasbourgeoises. Esprit frondeur à la personnalité angoissée, il souffre de troubles du comportement et de problèmes d'alcoolisme qui lui valent d'ailleurs une première hospitalisation en 1900.

Avec Bilder aus vergangener Zeit, Schnug atteint sa maturité stylistique dans ce qui apparaît comme une véritable synthèse de son œuvre. Il y déploie toute une iconographie entre scènes historiques, images inspirées des contes populaires alsaciens et vues pittoresques de Strasbourg à différentes époques. La planche 18 (Guldenturm) par exemple montre une vue de la tour du Florin (bâtiment détruit en 1876) sur le quai des Bateliers. La dernière planche, la seule en couleur, représente un collectionneur d'estampes sur fond d'or, rappelant les enluminures médiévales. Ce moyen-âge sublimé n'est pourtant pas l'unique source d'inspiration de Schnug. Marqué par la vie militaire, il pousse à l'extrême son souci du détail dans la représentation des uniformes et des armes du passé. L'intérêt archéologique tourne parfois à une précision obsessionnelle teintée d'archaïsme. Dans Vorposten (planche 6), il dessine minutieusement l'habit des grenadiers napoléoniens en faction dans un cimetière sous la neige, alors qu'Argentoratum (planche 32) figure une centurie romaine dans un paysage désolé à l'approche de l'enceinte de Strasbourg.

Le style de Schnug reste assez inclassable. La virtuosité de son trait et sa connaissance des costumes et des accessoires se déploient à travers son imaginaire fantasmatique. Son goût pour les bannières, les écussons et les marges donne un aspect décoratif à nombre d'images. L'artiste est tout autant marqué par l'art médiéval rhénan (surtout 


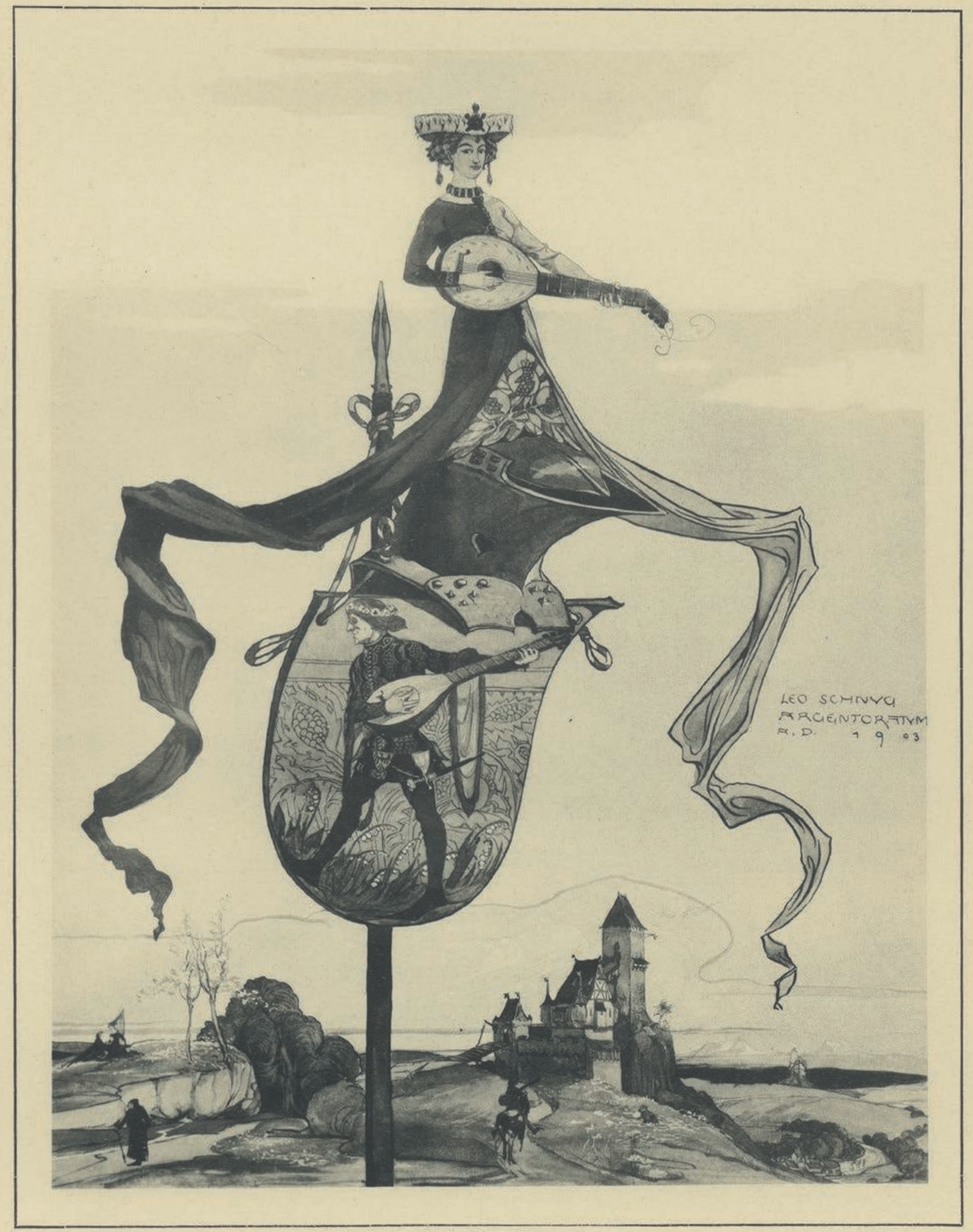

5 Frühling. 


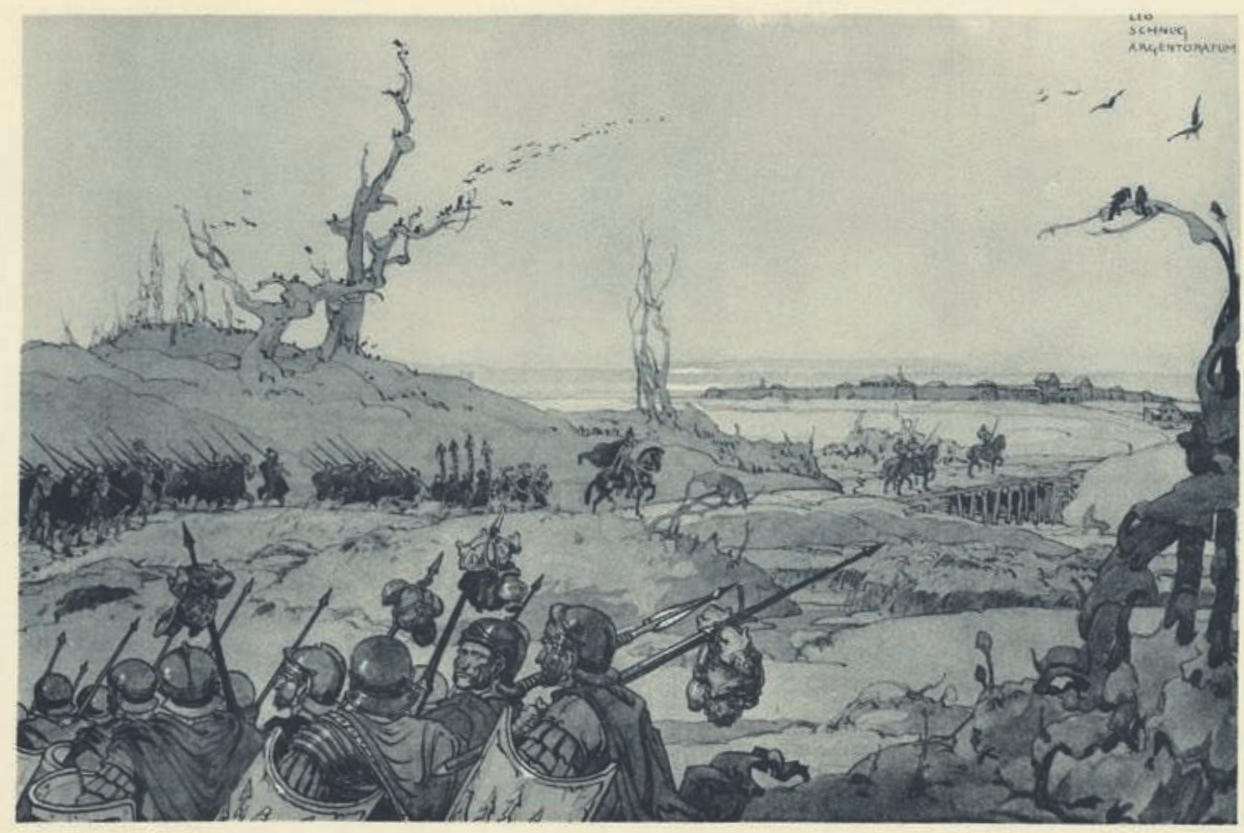

32 Argentoratum.

par les gravures sur bois qui sont pour lui une importante source d'inspiration) que par l'art de son temps. L'esprit du Jugendstil s'exprime par l'usage de l'arabesque que l'on retrouve dans les planches 5 (Frühling) ou 20 (Aufruhr).

Bilder aus vergangener Zeit synthétise l'ensemble de son travail et témoigne des dons de dessinateur de Schnug en donnant à voir tout l'éventail de son talent. Le succès de plusieurs des lithographies de l'album va se prolonger dans l'édition de cartes postales. Par la suite, sa carrière connaîtra son apogée en 1912 avec la fresque décorant la salle des fêtes du Haut-Kœnigsbourg. A la déclaration de guerre, il est enrôlé comme sous-officier dans l'armée allemande. Mais ses excès nombreux font qu'il sera assez rapidement réformé. Son état de santé, aggravé par ses abus d'alcool, se détériore. Sa déchéance s'accélère après la mort de sa mère en 1921. Après plusieurs séjours, il est définitivement interné à l'hôpital psychiatrique de Stephansfeld (près de Brumath). Il sombre dans la folie en 1924 et décède en 1933.

La filiation entre Léo Schnug et Tomi Ungerer est évidente, surtout après 1980, dans les scènes " alsaciennes " de ce dernier où il s'inspire délibérément de son aîné. On peut aussi voir en Schnug l'un des pères de la ligne claire en bande dessinée ; nous pensons ici plus particulièrement à Jacques Martin, autre dessinateur d'origine strasbourgeoise.

\section{Cédric Oberlé}

